\title{
IMC Based Design of PI Controller for Real Time Pressure Process
}

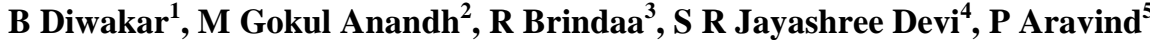 \\ Student, Instrumentation and Control Engineering, Saranathan College of Engineering, Tiruchirapalli, India ${ }^{1,2,3,4}$ \\ Assistant Professor, Instrumentation \& Control Engineering, Saranathan College of Engineering, Tiruchirapalli, India ${ }^{5}$
}

\begin{abstract}
The objective of the work is to maintain the pressure in the closed loop at desired set value. The pressurized tank has the features of nonlinearity, sluggishness by tuning conventional PI methods. This paper focus on implementation of internal mode control (IMC) to obtain an optimal PI control setting for pressure process. System identification of the process is done by process reaction curve method. To improve the robustness, internal model control method (IMC) is employed in tuning the PI controller and is applied to the First Order plus Time-Delay (FOPTD) model. Here delay is approximated with First Order plus Pade Approximation. At first, a Proportional Integral (PI) controller based on IMC-PI setting is designed and the results are compared with Ziegler Nichols (ZN) controller settings. The robustness of the controllers are endorsed by imposing both servo and regulatory disturbances. The simulation results confirm that IMC-PI controller has improved dynamic performance on disturbance rejection.
\end{abstract}

Keywords: IMC, Ziegler Nichols, PI controller, Pressure process.

\section{INTRODUCTION}

The PI control is the most commonly application of control strategy nowadays, with its simple arrangement, good robustness and wide application range, it is gradually highlighted in the control theory. It has been observed that, however, the existing PI controllers may not perform well in the complex control processes, such as the higher-order system and time-delay system. Efforts have been put to fix this problem, and numerous effective PI controller design and tuning methods for complex processes have been stated [1]

PI tuning has certainly been the key to reasonable performance and robustness. PI controller setting is proposed for several process model, especially for First Order plus Time Delay (FOPDT). There are two commonly used method of PI tuning, they are ZieglerNichols setting [2] and Cohen-coon setting [3], which still used in several industrial applications. Internal Model Control [4] allow system designer to specify the anticipated system behaviour. The robustness and performance of the model can controlled by the single parameter $(\lambda)$. IMC-PI setting is one of the greatest closedloop method among experts and researchers since it is the easy way to understand. In the context of IMC, Parameter of consequent close-loop models are enhanced with respect to error performance criteria such as Integral of Time Weighted Absolute Error (ITAE) [5], Integral Square Error (ISE) and Integral Absolute Error (IAE).

The Internal Model Control (IMC) structure offers an appropriate structure for satisfying the ideas. IMC [6] theory has been used earlier and autonomously by a number of other scholars. Using the IMC setting design technique, controller difficulty depends entirely on two factors: the difficulty of the model and the performance necessities indicated by the designer. IMC denotes to a methodical technique for control design based on the Qparameterization [7] idea that is the source for many current control methods. IMC offers an approach for

designing Q-parameterized controllers, has real-world appeal. As a result, IMC has been a widespread design technique in the chemical industries, mainly as a malicious for tuning single loop PID controllers.

The IMC setting design technique is rather broad and varied. It has been advanced in many arrangements including SISO (Single Input Single Output System), MIMO (Multi Input and Multi Output System), feedback plus feedforward IMC design. The paper focuses on the feedback SISO implementation technique for open-loop steady systems. IMC is supportive in evaluating the basic necessities related with feedback control. Such as determining the consequence of non-minimum stage elements on attainable control routine. Since the complexity of the IMC controller depends on the order of the system and control routine necessities, the IMC setting design technique is also supportive in defining when simple feedback control structure are acceptable.

\section{EXPERIMENTAL SETUP}

The physical experimental system comprises of process tank, pressure transmitter, control valve, pressure controller, air supply, current to pressure converter, vent valve, compressor, and air regulator

TABLE I: COMPONENTS OF EXPERIMENTAL SETUP

1. set point
2. vent valve
3. tank pressure
4. pressure transmitter
5. air supply
6. process tank
7. control valve
8. air supply
9. supply pressure
10. signal pressure
11. air regulator
12. I/P converter
13. pressure controller




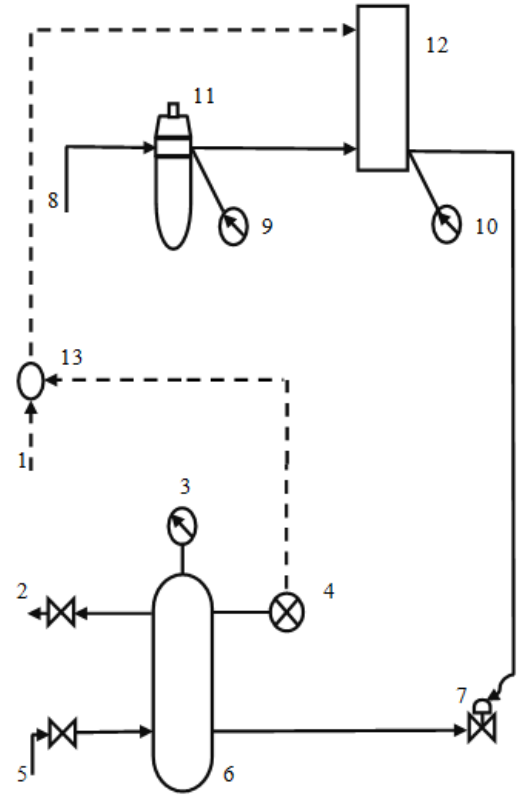

Fig.1 Piping and Instrumentation Diagram for Real time pressure process

TABLE II: Technical description of experimental setup

\begin{tabular}{|c|c|}
\hline Part name & Description \\
\hline Process tank & Opaque Pressure vessel \\
\hline $\begin{array}{l}\text { Pressure } \\
\text { transmitter }\end{array}$ & $\begin{array}{l}\text { Input } 4-20 \mathrm{~mA} \text {, Output } 4-20 \\
\text { psig }\end{array}$ \\
\hline Air filter regulator & Range $0-2.5 \mathrm{~kg} / \mathrm{cm}^{2}$ \\
\hline Control valve & $\begin{array}{l}\text { Type: Pneumatic, Size: 1/4", } \\
\text { Input: } 3-15 \text { psig, Air to close, } \\
\text { Linear }\end{array}$ \\
\hline Pressure gauge & $\begin{array}{l}\text { Range } 0-2.5 \quad \mathrm{~kg} / \mathrm{cm}^{2} \quad(1) \text {, } \\
\text { Range } 0-7 \mathrm{~kg} / \mathrm{cm}^{2}(2)\end{array}$ \\
\hline $\begin{array}{l}\text { Current to Pressure } \\
\text { converter }\end{array}$ & $\begin{array}{l}\text { Input } 4-20 \mathrm{~mA} \text {, Output 3-15 } \\
\text { psi }\end{array}$ \\
\hline Communication & RS232 \\
\hline
\end{tabular}

\section{A. System Identification - PRC method:}

Process Reaction Curve method is commonly used in system identification which is based on the step response. Process identification can be used to build a consistent model, after the process has been positioned in operation. There are several graphical user interface toolbox available for modelling. In this method, the small step change is introduced with the help of manual controller. For every input, the transient is recorded which is called process reaction curve. In the graph, a straight line is drawn tangent to the transient curve at the point of inflection. The tangent line intersects the curve in time axis at a point called Transportation lag $\left(\tau_{\mathrm{d}}\right)$. The apparent time constant $(\tau)$ and the steady state gain $\left(\mathrm{k}_{\mathrm{p}}\right)$ are measured [8]. The representation of s-shaped transient curve by FOPTD is given by

$$
G(s)=\frac{k_{p} e^{-\tau_{d}(\mathrm{~s})}}{\tau \mathrm{s}+1}
$$

Where $k_{p}$ is the steady state gain, $\tau_{d}$ is the apparent transport lag and $\tau$ is the apparent first order time constant [9]. The model is calculated with the real time parameters as

$$
G(s)=\frac{0.113 e^{-2 s}}{16 s+1}
$$

\section{CONTROLLER DESIGN}

This paper reports the implementation of PI parameters in two design setting. The ZN-PI method and IMC-PI control method. With these techniques, tuning of PI parameters is accomplished to achieve a robust design with the anticipated response time. PI controller is tuned by physically regulating design criteria in two design modes. The response has approximately the similar overshoot as proportional control, but the period is longer; however, the response proceeds to the set point after a comparatively extended settling period. The most advantageous effect of the integral action in the controller is the removal of offset.

\section{A. ZN based PI:}

The procedures were first suggested by Ziegler and Nichols. They established a closed-loop tuning technique still used today. The method is designated as a closed-loop method because the controller remains in the loop as an active controller in automatic mode. Ziegler and Nichols did not recommend that the ultimate gain $\mathrm{K}_{\mathrm{cu}}$ and ultimate period $\mathrm{P}_{\mathrm{u}}$ be computed from frequency response designs based on the model of the process. They proposed that $\mathrm{K}_{\mathrm{cu}}$ and $\mathrm{P}_{\mathrm{u}}$ be acquired from a closed-loop experiment of the real time process. When the instructions were first suggested, frequency response methods and process prototypes were not usually available to the control engineers. The guidelines are offered further down and are in the form that one would use for real application to an actual process.

After the process influences steady state at the usual level of operation, eliminate the integral and derivative modes of the controller, parting only proportional control. On some PID controllers, this needs that the integral period $t_{i}$ be fixed to its extreme value and the derivative time $t_{d}$ to its least value.

Select a value of proportional gain $\mathrm{K}_{\mathrm{c}}$, disturb the system, and detect the transient response. If the response falloffs, select an upper value of $\mathrm{K}_{\mathrm{c}}$ and again spot the response of the system. Remain increasing the gain in minor phases till the response first shows a sustained oscillation. The importance of gain and the period of oscillation that resemble to the continued oscillation are the ultimate gain $\left(\mathrm{K}_{\mathrm{u}}\right)$ and the ultimate period $\left(\mathrm{P}_{\mathrm{u}}\right)$.

\section{TABLE III: ZN-PI CONTROL PARAMETERS}

\begin{tabular}{|l|l|l|l|}
\hline Controller Type & $\mathrm{K}_{\mathrm{c}}$ & $\tau_{I}$ & $\tau_{D}$ \\
\hline Proportional (P) & $0.5 \mathrm{~K}_{\mathrm{u}}$ & - & - \\
\hline $\begin{array}{l}\text { Proportional- } \\
\text { Integral (PI) }\end{array}$ & $0.45 \mathrm{~K}_{\mathrm{u}}$ & $\mathrm{P}_{\mathrm{u}} / 1.2$ & - \\
\hline $\begin{array}{l}\text { Proportional- } \\
\text { Integral- } \\
\text { Derivative (PID) }\end{array}$ & $0.6 \mathrm{~K}_{\mathrm{u}}$ & $\mathrm{P}_{\mathrm{u}} / 2$ & $\mathrm{P}_{\mathrm{u}} / 8$ \\
\hline
\end{tabular}

\section{B. IMC based PI:}

Internal model control (IMC-PI) is based on a precise model based on the mathematical model of the process. The control system leads to stable and robust. A stable 
control system is one which keeps suitable control action for the dynamic changes in the control system.

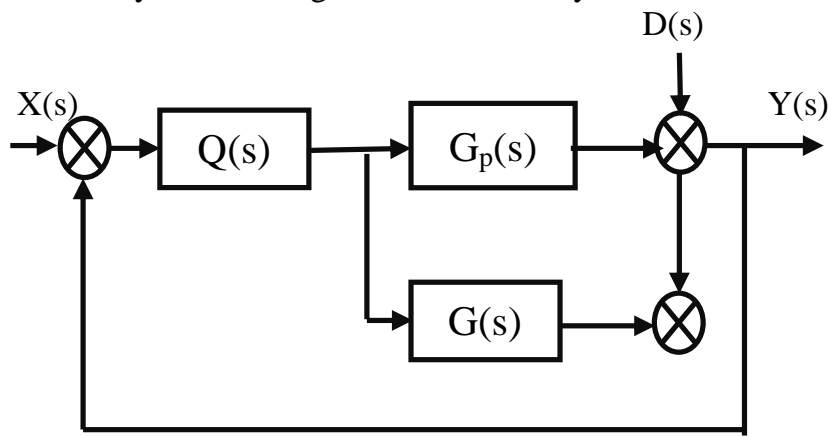

Fig. 2 IMC Structure

Here $\mathrm{Q}(\mathrm{s})$ is the IMC-PI controller, $\mathrm{G}_{\mathrm{p}}(\mathrm{s})$ is the process and $\mathrm{G}(\mathrm{s})$ is the model of the process and $\mathrm{X}(\mathrm{s}), \mathrm{Y}(\mathrm{s})$ and $\mathrm{D}(\mathrm{s})$ are the set-point, desired output and disturbance respectively. The dead time is approximated using first order pade method [10].

$$
G(s)=\frac{k_{p} e^{-\tau \mathrm{d}(\mathrm{s})}}{\tau \mathrm{s}+1}
$$

First order Pade approximation,

$$
e^{-\tau \mathrm{d}(\mathrm{s})}=\frac{-0.5 s+1}{0.5 s+1}
$$

IMC controller settings,

$$
\begin{gathered}
k_{p}=\frac{\tau+0.5 \tau_{d}}{\lambda\left(\tau_{c}+0.5 \tau_{d}\right)} \\
T_{i}=\tau+0.5 \tau_{d} \\
T_{d}=\frac{\tau \tau_{d}}{2 \tau+\tau}
\end{gathered}
$$

The robustness, disturbance rejection and dynamic performance of the system is openly associated to $\lambda$. If $\lambda$ is larger, the dynamic characteristics is poor with improved robustness [11]. If $\lambda$ is small, robust of the system will become worse and improved dynamic characteristics. So $\lambda$ selection plays a vital role in IMC-PI controller. Here $\lambda$ is assumed to be 0.6

If $\lambda$ is small, the dynamic performance of the system is good, but poor robustness; on the contrary, if $\lambda$ is larger, the robustness of the system will be improved, but the dynamic characteristics will become worse, so the selection of $\lambda$ need to compromise. The desired performance can be obtained by adjusting the filter time constant $\lambda$.

TABLE IV: CONTROLLER PARAMETERS

\begin{tabular}{|l|l|l|}
\hline Parameters & ZN-PI & IMC-PI \\
\hline $\mathrm{K}_{\mathrm{p}}$ & 52.2 & 94.0265 \\
\hline $\mathrm{K}_{\mathrm{i}}$ & 8.12925 & 5.53097 \\
\hline
\end{tabular}

\section{RESULT AND COMPARISION}

The controller parameters are calculated and applied for set point 10 psi shown in figure 3 . The servo response of the system was witnessed by giving set points of $10 \mathrm{psi}, 20$ psi. The deviation of pressure from reference point is noted shown in figure 5

\section{TABLE V: COMPARISION OF PERFORMANCE INDEX}

\begin{tabular}{|l|l|l|}
\hline Specification & ZN-PI & IMC-PI \\
\hline ISE & 303.5 & 223.9 \\
\hline ITAE & 2167 & 1060 \\
\hline IAE & 73.5 & 39.89 \\
\hline
\end{tabular}

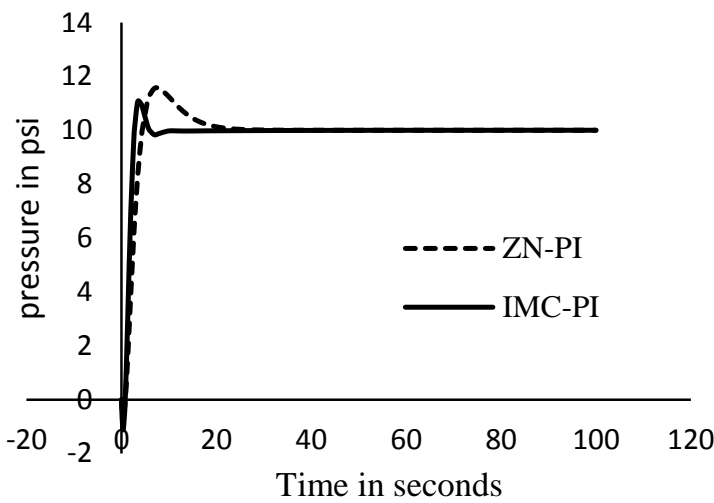

Fig. 3 Comparison of ZN-PI and IMC-PI for a setpoint of $10 \mathrm{psi}$

Load change response of a process for PI controller is shown is figure 3 and it evidently states how quick the IMC-PI reacts to disturbance compared to ZN-PI setting.

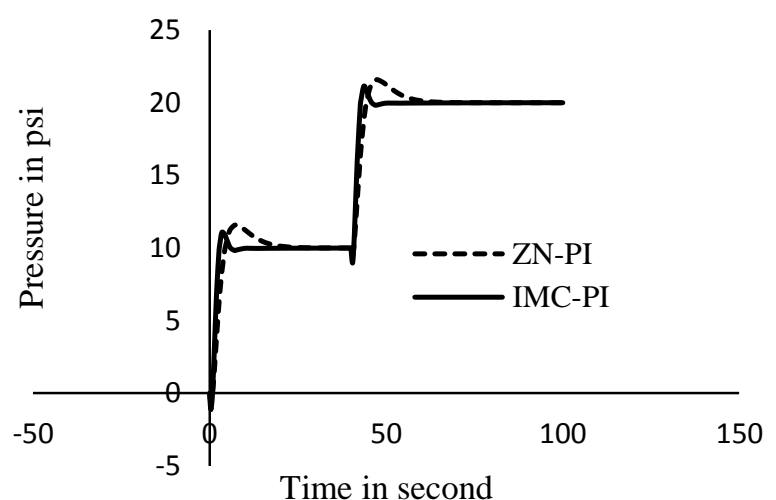

Fig. 4 Servo Response of a process

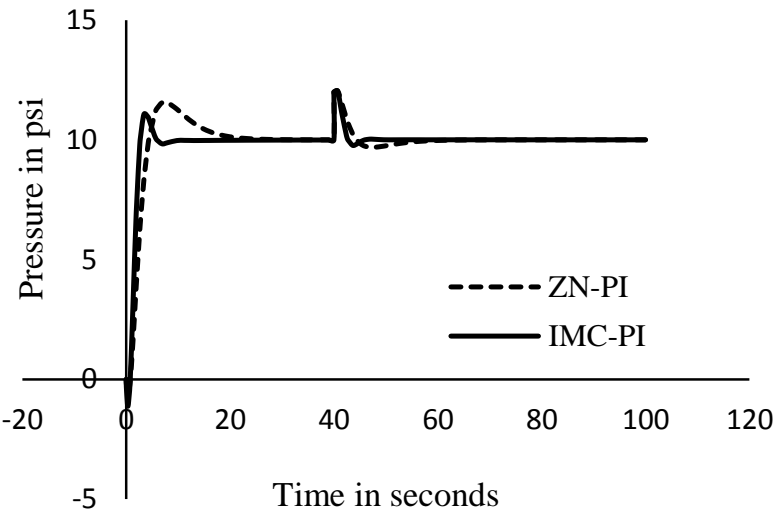

Fig. 5 Regulatory Response of a process

\section{CONCLUSION}

We have proposed an effective method to design the PI controller that can be implemented in real time pressure process. The result is shown that IMC-PI controller have 
given good results than ZN-PI controller. From the consequences, the response of IMC was shown satisfactory in terms of ISE, IAE and ITAE when compared to the ZN-PI setting. From the response, it is witnessed that the IMC-PI tracks the setpoint with less oscillation when compared to ZN-PI setting. The simulation results has proven that IMC-PI control setting is more effective way in disturbance rejection and to enhance the stability of system.

\section{REFERENCES}

[1] Zhao Kun-long and Wang Zai-ying (2015), Application of boiler superheated steam pressure control which based on IMC-PID, IEEE, ISBN-978-1-4799-7016-2 pp-586-589, 2015

[2] J. G. Ziegler and N. B. Nichols (1942), Optimum settings for automatic controllers, Trans. Amer. Soc. Mech. Eng., vol. 64, pp. $759-768,1942$

[3] G.H Cohen and G.A Coon, Theoretical Consideration of Retarded Control, Trans ASME 75, pp.827/834, 1953

[4] Chien, I.L., and Fruehauf, P.S., "Consider IMC Tuning to Improve Controller Performance", Chem. Eng. Prog. pp.33-41, 1990

[5] Y. M. Zhao, W. F. Xie and X. W. Tu, Performance-based parameter tuning method of model-driven PID control systems, ISA Trans., vol. 51, no.3, pp. 393-399, 2012.

[6] Garcia, C.E Pret and D.M. Morari, Model Predictive Control Theory and Practice - A Survey, Automatica 25 (3): 335-348, doi:10.1016/0005-1098(89)90002-2,1989

[7] Economou, C.G and M.Morari, Internal Model Control. 5. Extension to Nonlinear Systems, Ind. Eng. Chem. Process Des. Dev. 25, 303, 1982

[8] D. R. Coughanowar, Process Systems Analysis and Control, Tata McGraw Hill, 1991.

[9] P Aravind, M Valluvan, B Sangeetha, Model Based Controller Design for Level Process, International Journal for Computer Applications, Vol.88- No.18, 2014.

[10] W. B. Bequette, Process Control Modeling and Simulation, Prentice Hall, 2003.

[11] P Aravind and M Valluvan, PSO Based Optimization of a PID Controller for a Linear Tank Level Control Process, International Journal of Current Engineering and Technology, Vol-4, No.2, pp. 486-490, 2014 